\title{
Blood Pressure Variability in Tetraplegic Patients with Autonomic Hyperreflexia
}

\author{
H. Krum, ${ }^{1}$ MBBS, L. G. Howes, ${ }^{1}$ PhD, FRACP, D. J. Brown, ${ }^{2}$ MD, \\ FRACP, W. J. Louis, ${ }^{1}$ MD, FRACP ${ }^{1}$ Department of Medicine, Clinical Phar- \\ macology and Therapeutics, ${ }^{2}$ Spinal Injuries Units, Austin Hospital, Heidelberg, \\ Victoria, 3084, Australia.
}

\begin{abstract}
Summary
Autonomic hyperreflexia $(A H)$ is a syndrome characterised by profound pressor responses, sweating and headache which occurs in tetraplegic patients in response to a variety of stimuli below the level of cord injury. The pathogenesis of this syndrome is unclear but may be associated with increased blood pressure $(B P)$ variability in these patients. To investigate this possibility, 24 hour ambulatory BP monitoring was performed utilising the Spacelabs 5300 Ambulatory BP system in 30 patients: 10 normal subjects, 10 spinal cord injury (SCI) patients who had never experienced $A H$ and 10 SCI patients who had experienced recent episodes of $A H$ (but with no symptoms during the study period). There were no statistically significant differences in systolic $B P(S B P)$, diastolic $B P(D B P)$ or heart rate $(H R)$ between the three groups. The average of the coefficients of variation of SBP, DBP and HR within each subject over the study period were calculated. Tetraplegic patients who had recently experienced episodes of $A H$ had greater $S B P, D B P$ and $H R$ variability than normal persons $(p<0.01, p<0.005, p<0.005)$ and greater DBP and HR variability than SCI patients who had never experienced $A H(p<0.01$. $p<0.05)$. AH may represent the symptoms associated with the upper extremes of this BP variability. The increased variability may be the result of enhanced cardiovascular responsiveness to noradrenaline and arginine vasopressin or because of the absence of descending inhibitory pathways in the decentralised cord that would normally suppress spinal sympathetic reflexes.
\end{abstract}

Key words: Tetraplegia; Blood pressure; Autonomic hyperreflexia.

Autonomic hyperreflexia $(\mathrm{AH})$ is a syndrome characterised by profound pressor responses, sweating and headache which occurs in tetraplegic patients in response to a variety of stimuli below the level of cord injury (Head and Riddoch, 1917; Guttmann and Whitteridge, 1947). The pathogenesis of this syndrome is unclear. It is possible that blood pressure (BP) variability increases in some patients with spinal cord injury (SCI) compared to normal persons and that episodes of $\mathrm{AH}$ represent symptoms associated with the upper extremes of this 
variability. To test this hypothesis, blood pressure variability was assessed utilising 24 hour ambulatory BP monitoring in patients with spinal cord injury who were currently experiencing episodes of hyperreflexia, patients with spinal cord injury who had never experienced episodes of hyperreflexia and in normal volunteers.

\section{Methods}

\section{Patients and normal subjects}

BP monitoring was performed in 30 patients: 10 normal persons consisting of medical students and Clinical Pharmacology Unit staff members with no medical problems and on no medications, 10 SCI patients never having experienced episodes of $\mathrm{AH}$, and $10 \mathrm{SCI}$ patients currently experiencing episodes of hyperreflexia. The spinal patients were on no cardiovascular medications apart from anticholinergics which were not altered during the study period. Groups were matched as closely as possible for age, sex, duration of injury and level of transection.

The tetraplegic patients with recent episodes of $\mathrm{AH}$ were required to have 2 documented episodes of $\mathrm{AH}$ in the prior 7 days, consisting of a rise in systolic $\mathrm{BP}$ (SBP) of $>30 \mathrm{~mm} \mathrm{Hg}$ or diastolic BP (DBP) of $>20 \mathrm{~mm} \mathrm{Hg}$, as well as at least one associated symptom consisting of either sweating, flushing or headache. In addition, if symptoms occurred during the period of ambulatory monitoring, that data was excluded and the monitoring repeated. There were no restrictions on physical activity undertaken during the study period in any group.

\section{BP monitoring}

Twenty four hour ambulatory BP monitoring was performed using the Spacelabs 5300 Ambulatory Blood Pressure System (Spacelabs, Hillsboro, Oregon, USA) SBP, DBP and heart rate (HR) were recorded automatically half hourly from 06:00 to midnight, then hourly overnight. The device was calibrated against mercury sphygmomanometer recordings prior to commencement of recordings in each patient. Artefactual recordings (pulse pressure $<10 \mathrm{~mm} \mathrm{Hg}$, heart rate less than $30 \mathrm{bpm}$ or greater than $160 \mathrm{bpm}$ ) were excluded. At least 25 nonartefactual BP and HR recordings were required within the 24 hour period to be included in the study.

\section{Statistical analysis}

The mean and standard deviation for SBP, DBP and HR over 24 hours were obtained for each individual and the average value for the group determined. A coefficient of variation (CV) for SBP, DBP and HR was obtained for each of the subjects and used as a measure of blood pressure and heart rate variability over the study period. One way analysis of variance was used to compare mean 24 hour blood pressure and heart rate variability between the three groups. 


\section{Results}

Demographic data is summarised in Table I. Although the patients having experienced recent $\mathrm{AH}$ were generally younger than the other groups, this difference did not reach statistical significance. Mean SBP, DBP and HR values for the three groups are displayed in Table II. There was no significant difference in mean SBP, DBP or HR between the three groups. The average of the coefficients of variation for SBP, DBP and HR within individuals are displayed in the Figure. Spinal patients who had recently experienced $\mathrm{AH}$ had significantly greater CV's for SBP, DBP and HR than normal persons and significantly greater coefficients of variation for DBP and HR than patients who had never experienced $\mathrm{AH}$. Although the CV's for all 3 parameters were higher in the SCI without AH group than in normal persons, the difference did not reach statistical significance. In order to investigate whether the difference in BP and HR variability between SCI patients with $\mathrm{AH}$ and SCI patients without $\mathrm{AH}$ could have been due to differences in the level of spinal transection, SCI patients without $\mathrm{AH}$ were further divided into those with SCI levels above and below T6-the level below which SC injury is rarely complicated by AH (Guttmann and Whitteridge, 1947) (Table III). There was no significant difference in BP or HR levels, nor in variability of these parameters when the group was subdivided in this way. However, it should be emphasised that in view of the small number of SCI patients looked at in this subgroup comparison, the statistical power to detect differences between them would be small.

Table I Demographic data of Spinal Cord Injury patients and normal persons used for studies of 24 hour blood pressure and heart rate variability. Although the spinal cord injury patients who had recently experienced autonomic hyperreflexia $(\mathrm{AH})$ were on average younger than the other two groups, the difference was not statistically significant (one way analysis of variance). Age values are the mean \pm standard error of mean.

\begin{tabular}{|c|c|c|c|c|c|c|c|}
\hline & \multirow[b]{3}{*}{ Age } & \multirow{3}{*}{$\begin{array}{l}\text { Sex } \\
M\end{array}$} & \multirow[b]{3}{*}{$\mathrm{F}$} & \multicolumn{2}{|c|}{$\begin{array}{l}\text { Level of lesion } \\
\text { (no. patients) }\end{array}$} & \multirow{2}{*}{\multicolumn{2}{|c|}{$\begin{array}{l}\text { Time from injury } \\
\text { (no. patients) }\end{array}$}} \\
\hline & & & & Above & T6 or & & \\
\hline & & & & T6 & below & $<6 / 12$ & $>6 / 12$ \\
\hline Normal persons $(n=10)$ & $\begin{array}{l}33 \cdot 4 \\
\pm 3 \cdot 2\end{array}$ & 6 & 4 & - & - & - & - \\
\hline $\begin{array}{l}\text { SCI patients without } \mathrm{AH} \\
(\mathrm{n}=10)\end{array}$ & $\begin{array}{l}36 \cdot 2 \\
\pm 4 \cdot 5\end{array}$ & 8 & 2 & 6 & 4 & 5 & 5 \\
\hline $\begin{array}{l}\text { Recent AH patients } \\
(\mathrm{n}=10)\end{array}$ & $\begin{array}{l}23 \cdot 3 \\
\pm 2 \cdot 0\end{array}$ & 9 & 1 & 10 & 0 & 5 & 5 \\
\hline
\end{tabular}

Table II Mean ( \pm standard error of the mean (SEM)) of average 24 hour blood pressures (BP) and heart rates in normal volunteers, spinal cord injury (SCI) patients who had never experienced autonomic hyperreflexia $(\mathrm{AH})$ and SCI patients who had recently experienced $\mathrm{AH}$. There was no significant difference in any of the parameters between the three groups (one way analysis of variance).

\begin{tabular}{llll}
\hline Mean \pm SD & $\begin{array}{l}\text { Systolic BP } \\
\text { mean } \pm \text { SEM }\end{array}$ & $\begin{array}{l}\text { Diastolic BP } \\
\text { mean } \pm \text { SEM }\end{array}$ & $\begin{array}{l}\text { Heart rate } \\
\text { mean } \pm \text { SEM }\end{array}$ \\
\hline Normal persons $(\mathrm{n}=10)$ & $118 \cdot 41 \pm 4 \cdot 30$ & $78 \cdot 83 \pm 2 \cdot 79$ & $77 \cdot 06 \pm 2 \cdot 24$ \\
SCI patients without AH $(\mathrm{n}=10)$ & $116 \cdot 24 \pm 4 \cdot 80$ & $69 \cdot 72 \pm 4 \cdot 41$ & $79 \cdot 13 \pm 2 \cdot 91$ \\
Recent AH patients $(\mathrm{n}=10)$ & $118 \cdot 24 \pm 4 \cdot 91$ & $74 \cdot 54 \pm 3 \cdot 48$ & $88 \cdot 24 \pm 3 \cdot 82$ \\
\hline
\end{tabular}




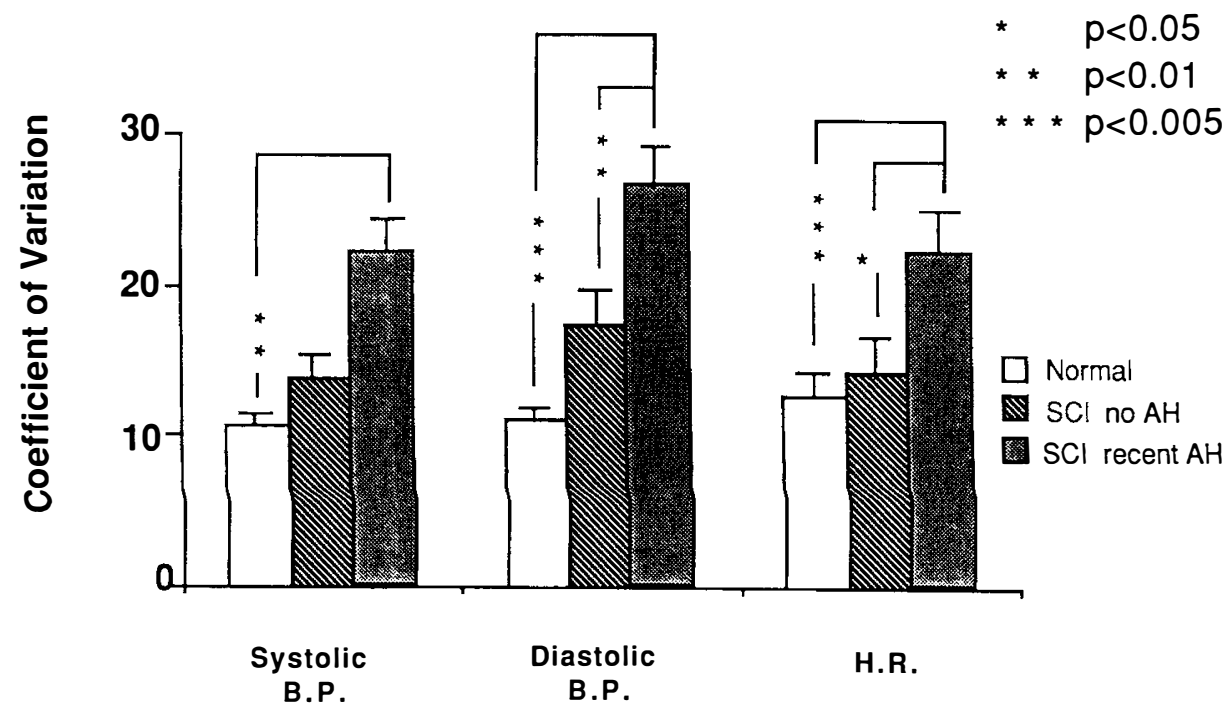

Figure Average values ( \pm standard error of mean) for the coefficients of variation of blood pressure (BP) and heart rates (HR) over a 24 hour period in normal persons, spinal cord injury (SCI) patients who had never experienced autonomic hyperreflexia (AH) and SCI patients who had recently experienced $\mathrm{AH}$. SCI patients with recent $\mathrm{AH}$ had significantly greater variability of diastolic BP and HR than both normal subjects and SCI patients without $\mathrm{AH}$, and significantly greater variability of systolic BP than normal persons. (One way analysis of variance, pairwise comparisons by Student's t-test with Bonferonni correction).

Table III Blood pressure variability in spinal cord injury (SCI) patients who had never experienced autonomic hyperreflexia (AH) analysed according to SCI level' Patients with SCI above T6 did not differ in their blood pressure or heart rate variability to those with SCI below T6 (Student's unpaired t-test). Values are mean \pm standard error of mean (SEM).

\begin{tabular}{|c|c|c|c|c|c|}
\hline & Number & Systolic BP & $(\mathrm{mm} \mathrm{Hg})$ & Diastolic BP (mm Hg) & HR (beats $/ \mathrm{min}$ ) \\
\hline SCI level & $\begin{array}{l}\text { of } \\
\text { patients }\end{array}$ & Mean & $\mathrm{CV}$ & Mean & Mean \\
\hline Above T6 & 6 & $109 \cdot 48 \pm 4 \cdot 33$ & $12 \cdot 9 \pm 2 \cdot 74$ & $70 \cdot 11 \pm 4 \cdot 35 \quad 17 \cdot 72 \pm 6 \cdot 63$ & $78 \cdot 07 \pm 3 \cdot 28 \quad 15 \cdot 25 \pm 3 \cdot 01$ \\
\hline $\begin{array}{l}\text { T6 or } \\
\text { below }\end{array}$ & 4 & $126 \cdot 36 \pm 8 \cdot 29$ & $14 \cdot 5 \pm 1 \cdot 50$ & $68 \cdot 14 \pm 9 \cdot 88 \quad 16 \cdot 65 \pm 1 \cdot 86$ & $80 \cdot 71 \pm 5 \cdot 90 \quad 12 \cdot 64 \pm 2 \cdot 34$ \\
\hline
\end{tabular}

\section{Discussion}

Blood pressure variability has been previously described in normotensive and hypertensive non-SCI subjects using 24 hour ambulatory BP recordings (Reeves et al., 1983). Age, sex, level of blood pressure and antihypertensive treatment did not appear to alter BP variability when assessed using this method. Our results demonstrate significantly greater BP variability in SCI patients having recently experienced $\mathrm{AH}$. These patients did not experience $\mathrm{AH}$ during the study period, therefore the increased BP variability in these patients could not be attributed simply to further episodes of $\mathrm{AH}$ during the course of the study.

The pathogenesis of the increased BP variability in $\mathrm{AH}$ patients is unclear. Chronic SCI patients have enhanced blood pressure rises during noradrenaline infusions (Christensen, Frankel, Mathias, Spalding, 1975; Mathias, Frankel, 
Christensen, Spalding, 1976). This may indicate an increased sensitivity of adrenoceptor mediated responses resulting from reduced sympathetic nerve activity below the level of cord injury, or merely occur because of an impaired baroreceptor reflex arc which would normally tend to suppress rises in BP during infusions of pressor substances. Similarly, an enhanced pressor response to arginine vasopressin (AVP) at plasma levels within the physiological range has recently been demonstrated (Poole, Williams, Lightman, Frankel, 1987). A greater than normal rise in plasma levels of both hormones in SCI patients is seen with physiological stimuli such as orthostasis (Mathias, Christensen, Corbett, Frankel, Goodwin, Peart, 1975; Sved, McDowell, Blessing, 1985; Poole, 1987). Thus minor alterations in posture or physical activity may trigger an exaggerated cardiovascular homeostatic response with a resultant increase in BP variability.

Relatively minor stimuli associated with the development of $\mathrm{AH}$, such as bladder or bowel distension, may initiate enhanced blood pressure responses because of an absence of descending spinal inhibitory pathways which normally suppress spinal sympathetic reflexes. These reflexes can therefore become amplified and generalised in the isolated cord and lead to both rises in BP and associated autonomic symptoms. Although not statistically significant, the somewhat higher than normal BP variability in spinal patients never having experienced $\mathrm{AH}$ is in keeping with this postulate of an enhanced hemodynamic response to minor stimuli in SCI patients.

In conclusion, tetraplegic patients who have recently experienced episodes of $\mathrm{AH}$ have greater BP variability than normal persons and patients with spinal cord injury who have never experienced $\mathrm{AH}$. AH may represent the symptoms associated with the upper extremes of this BP variability. The measurement of 24 hour BP variability may provide a useful index of cardiovascular instability in spinal patients, and of the potential efficacy of therapies for the prophylaxis of $\mathrm{AH}$.

\section{References}

Christensen NJ, Frankel HL, Mathias CJ, et al. 1975 Enhanced pressor response to noradrenaline in human subjects with chronic sympathetic decentralization. fournal of Physiology 252:39-40.

GutTMANN L, WhitTERIDGE D 1947 Effects of bladder distension on automatic mechanisms after spinal cord injury. Brain 70:361.

HEAD H, RidDOCH G 1917 The automatic bladder, excessive sweating, and some other reflex conditions in gross injuries of the spinal cord. Brain 40:188.

Mathias CJ, Christensen NJ, Corbett JL, et al. 1975 Plasma catecholamines, plasma renin activity and plasma aldosterone in tetraplegic man, horizontal and tilted. Clinical Science and Molecular Medicine 49:291-299.

Mathias CJ, Frankel HL, Christensen NJ, et al. 1976 Enhanced pressor response to Noradrenaline in patients with cervical spinal cord transection. Brain 99:757-770.

Poole CJM, Williams TDM, Lightman SL, et al. 1987 Neuroendocrine control of vasopressin secretion and its effect on blood pressure in subjects with spinal cord transection. Brain 110: 727-735.

ReEves RA, JohnSON AM, Shapiro AP, et al. 1983 Ambulatory blood pressure monitoring: methods to assess severity of hypertension, variability and sleep changes. Ambulatory Blood Pressure Monitoring, Steinkopff Verlag Darmstadt, Springer-Verlag, New York, pp 27-34.

Sved AF, McDowell FH, Blessing WW 1985 Release of anti-diuretic hormone in quadriplegic subjects in response to head up tilt. Neurology 35:78-82. 